\title{
Management of Acute Radiodermatitis in Non-Melanoma Skin Cancer Patients Using Electrospun Nanofibrous Patches Loaded with Pinus halepensis Bark Extract
}

\author{
Aikaterini Kyritsi ${ }^{1}$, Stefanos Kikionis ${ }^{2}{ }^{\circ}$, Anna Tagka ${ }^{3}$, Nikolaos Koliarakis ${ }^{3}$, Antonia Evangelatou ${ }^{3}$, \\ Panagiotis Papagiannis ${ }^{3}$, Alexandros Stratigos ${ }^{3}$, Vangelis Karalis ${ }^{1}{ }^{1}$, Paraskevas Dallas ${ }^{1}$, Andreas Vitsos ${ }^{1}{ }^{1}$, \\ Efstathia Ioannou ${ }^{2} \mathbb{D}$, Vassilios Roussis $2, * \mathbb{D}$ and Michail Rallis ${ }^{1, *} * \mathbb{C}$
}

1 Section of Pharmaceutical Technology, Department of Pharmacy, School of Health Sciences, National and Kapodistrian University of Athens, Panepistimiopolis Zografou, 15784 Athens, Greece; katerinakyr18394@gmail.com (A.K.); vkaralis@pharm.uoa.gr (V.K.); dallas@pharm.uoa.gr (P.D.); avitsos@yahoo.gr (A.V.)

2 Section of Pharmacognosy and Chemistry of Natural Products, Department of Pharmacy, School of Health Sciences, National and Kapodistrian University of Athens, Panepistimiopolis Zografou, 15771 Athens, Greece; skikionis@pharm.uoa.gr (S.K.); eioannou@pharm.uoa.gr (E.I.)

3 First Department of Dermatology-Venereology, National and Kapodistrian University of Athens,

check for updates

Citation: Kyritsi, A.; Kikionis, S.; Tagka, A.; Koliarakis, N.;

Evangelatou, A.; Papagiannis, P.; Stratigos, A.; Karalis, V.; Dallas, P.; Vitsos, A.; et al. Management of Acute Radiodermatitis in Non-Melanoma Skin Cancer Patients Using Electrospun Nanofibrous

Patches Loaded with Pinus halepensis Bark Extract. Cancers 2021, 13, 2596. https://doi.org/10.3390/ cancers13112596

Academic Editors: Meritxell Arenas and Pierfrancesco Franco

Received: 23 April 2021

Accepted: 22 May 2021

Published: 26 May 2021

Publisher's Note: MDPI stays neutral with regard to jurisdictional claims in published maps and institutional affiliations.

Copyright: (c) 2021 by the authors. Licensee MDPI, Basel, Switzerland. This article is an open access article distributed under the terms and conditions of the Creative Commons Attribution (CC BY) license (https:/ / creativecommons.org/licenses/by/ $4.0 /)$. Andreas Syggros Hospital, 5 Ionos Dragoumi Str., 11621 Athens, Greece; annatagka@gmail.com (A.T.); nkoliarakis@yahoo.gr (N.K.); antevagelatou@gmail.com (A.E.); PPaPagi@med.uoa.gr (P.P.); alstrat2@gmail.com (A.S.)

* Correspondence: roussis@pharm.uoa.gr (V.R.); rallis@pharm.uoa.gr (M.R.); Tel.: +30-210-727-4592 (V.R.); +30-210-727-4699 (M.R.)

Simple Summary: The most frequent adverse effect for patients receiving radiotherapy, an effective treatment for skin cancer when surgical removal of the tumor is impossible, is acute radiodermatitis, affecting patients' physical function and often leading to therapy termination. Creams and other topical formulations used so far for the prevention of acute radiodermatitis are applied at regular intervals but do not ensure a constant and controlled transepidermal absorption. The aqueous extract of Aleppo pine bark, previously preclinically and clinically assessed in the form of gel, was herein loaded on micro/nanofibrous patches and clinically evaluated in comparison with a commercially used reference cream on non-melanoma skin carcinoma patients undergoing radiotherapy. The experimental patch significantly contributed to prophylaxis and successful management of acute radiodermatitis, safely restoring skin and its biophysical parameters to normal levels and reducing patients' discomfort. Topical application of pine-loaded micro/nanofibrous patches holds great potential for the development of a new generation of anti-inflammatory skin care dressings against radiodermatitis.

Abstract: Acute radiodermatitis is the most common side effect in non-melanoma skin cancer patients undergoing radiotherapy. Nonetheless, despite the ongoing progress of clinical trials, no effective regimen has been found yet. In this study, a non-woven patch, comprised of electrospun polymeric micro/nanofibers loaded with an aqueous extract of Pinus halepensis bark (PHBE), was fabricated and clinically tested for its efficacy to prevent radiodermatitis. The bioactivity of the PHBE patch was evaluated in comparison with a medical cream indicated for acute radiodermatitis. Twelve volunteer patients were selected and randomly assigned to two groups, applying either the PHBE patch or the reference cream daily. Evaluation of radiation-induced skin reactions was performed during the radiotherapy period and 1 month afterwards according to the Radiation Therapy Oncology Group (RTOG) grading scale, photo-documentation, patient-reported outcomes (Visual Analog Scale, questionnaire), biophysical measurements (hydration, transepidermal water loss, erythema, melanin), and image analysis. In contrast with the reference product, the PHBE patch showed significant antiinflammatory activity and restored most skin parameters to normal levels 1 month after completion of radiation therapy. No adverse event was reported, indicating that the application of the PHBE patch can be considered as a safe medical device for prophylactic radiodermatitis treatment. 
Keywords: acute radiodermatitis; radiation therapy; non-melanoma skin cancer; patients; Pinus halepensis bark extract; electrospun nanofibrous patches; anti-inflammatory activity

\section{Introduction}

Skin cancer is one of the most common malignancies, constituting an important public health concern [1]. Non-melanoma skin cancer (NMSC) includes mainly basal cell carcinoma (BCC), squamous cell carcinoma (SCC), and basosquamous carcinoma (BSC) with features of both basal cell and squamous cell carcinomas [2-6]. The factors that are implicated in NMSC etiopathogenesis include chronic ultraviolet (UV) radiation exposure, phototype, age, gender, immunosuppression, smoking, and genetic factors [1,7-9]. NMSC is relatively non-lethal and non-invasive, while its incidence varies among race and region. It mainly occurs on the head and neck, anatomical sites which are frequently treated with X-ray therapy $[4,7,8]$.

Radiation therapy (RT) is an effective alternative treatment when surgical removal is contraindicated due to the tumor's anatomical site or patient comorbidities [8,10]. Orthovoltage $\mathrm{X}$-ray therapy is considered as one of the traditional approaches for treating skin cancer and covers an X-ray energy range of 150-300 kV, damaging DNA cancer cells either directly or through free radical generation [11,12]. However, as with other cancer treatments, RT is also associated with side effects [13]. Acute radiodermatitis is the most frequent adverse effect in patients undergoing radiotherapy [14]. Its severity depends on the dose per fraction, the total dose, and the individual's sensitivity [13-16]. Onset of acute radiodermatitis may occur between 15 days to 3 months after the beginning of the treatment and ranges from faint erythema to dry desquamation, moist desquamation, and ulceration $[13,15,17]$. Radiation-induced skin injury may impair the patient's physical functioning and compliance with therapy $[17,18]$.

Clinical practice guidelines for the prophylaxis and management of acute radiodermatitis include a variety of topical, oral, and intravenous agents [14,19]. Surveys suggest that topical products, such as creams, gels, and lotions, should be used to protect and promote tissue repair in patients with radiation-induced dermatitis $[19,20]$. The main disadvantage of the application of such products is the non-controlled dosage, which leads to incomplete preventive and therapeutic effects [19]. Numerous topical formulations have been clinically studied in radiation-induced skin injuries without providing sustainable treatment strategies $[14,18,19,21]$.

The advantage of topical patches, which have yet to be evaluated for the management of radiodermatitis in NMSC patients, may be the controlled delivery of anti-inflammatory agents [22-26]. The inflamed area and surrounding skin can be effectively protected against microbial contamination by biocompatible composite dressings [27-29].

Over the last few years, nanotechnology has risen as one of the most promising technologies in the development of patches for biomedical applications. Nanofibrous nonwovens are steadily attracting increasing interest for their application as wound dressings, controlled drug release systems, and tissue regeneration scaffolds [29-32]. Exhibiting high surface-area-to-volume ratio, high porosity, and tunable mechanical strength, electrospun fibers with a size in the micro/nanoscale can be easily generated through electrically charged polymeric solutions or melts $[33,34]$. Under the application of a high-voltage electric field, various synthetic and natural polymers or blends can be fabricated in micro/nanofibrous matrices with a structural similarity to the natural extracellular matrix, affording high drug loading efficacy and displaying tunable mechanical properties. Moreover, the incorporation of suitable bioactive substances into the polymeric fibers of various biodegradable and biocompatible polymers can lead to multifunctional topical dressings with anti-inflammatory properties [35-39].

Species of the genus Pinus are well known for their medicinal properties, which are related to their chemical composition. Their cones, needles, and bark extracts, as well as 
their essential oils, have been utilized for many pharmaceutical applications, demonstrating cytotoxic, analgesic, antiviral, antioxidant, antimicrobial, and/or anti-inflammatory activities [40-45]. In the Mediterranean region, Pinus halepensis Miller (Aleppo pine) represents one of the most common naturally growing conifer species. Its aqueous bark extract (PHBE) is rich in antioxidant polyphenolic agents, consisting mainly of procyanidins and phenolic acids.

Herein, motivated by the promising results of our previous studies, which showed that PHBE can significantly prevent and/or decrease skin damage caused by UV radiation or X-ray irradiation $[16,26,46]$, non-woven polymeric micro/nanofibrous patches loaded with PHBE were prepared and clinically evaluated for their ability to prevent acute radiodermatitis in NMSC patients undergoing radiotherapy (Figure S1). The PHBE micro/nanofibrous patch was morphologically and physicochemically characterized by scanning electron microscopy (SEM), as well as thermogravimetric (TGA) and differential scanning calorimetry (DSC) analyses. The efficiency of the micro/nanofibrous PHBE dressing was evaluated in comparison with a medical cream indicated for acute radiodermatitis. The clinical evaluation was conducted on 12 volunteer patients randomly assigned to two groups, applying either the PHBE patch or the reference cream daily. The radiation-induced skin reactions were evaluated during the period receiving radiotherapy and 1 month afterwards according to the Radiation Therapy Oncology Group (RTOG) grading scale, photo-documentation, patient-reported outcomes (Visual Analog Scale (VAS), questionnaire), measurements of the skin's biophysical parameters (hydration, transepidermal water loss (TEWL), erythema, melanin), and image analysis.

\section{Materials and Methods}

\subsection{Materials}

Polyethylene oxide (PEO) (MW 8,000,000) and cellulose acetate (CA) (MW 50,000) were purchased from Sigma-Aldrich (Darmstadt, Germany). Sodium alginate (SA) (MW 216,121) was purchased from Cellco Chemicals SA. P. halepensis bark was collected from Kaisariani forest, a suburb near Athens, Greece, and pulverized in a blender. The bark was extracted with $\mathrm{dH}_{2} \mathrm{O}\left(1: 10\right.$ ratio for $48 \mathrm{~h}$ at $\left.40^{\circ} \mathrm{C}\right)$ and subsequently filtered and freeze-dried to produce a dark red powder. All chemical reagents used were of analytical grade.

\subsection{Preparation of the Electrospun Micro/Nanofibrous Patch}

The PHBE micro/nanofibrous patches were prepared by electrospinning CA/PHBE and PEO/SA spinning solutions as previously described, with slight modifications [26]. For preparation of the CA/PHBE spinning solution, $\mathrm{CA}$ at $9 \% w / v$ and PHBE at $2 \% w / v$ were dissolved in $\mathrm{Me}_{2} \mathrm{CO} / \mathrm{H}_{2} \mathrm{O}(9: 1 \mathrm{v} / \mathrm{v})$. The $\mathrm{PEO} / \mathrm{SA}$ solution was prepared in $\mathrm{H}_{2} \mathrm{O}$ by dissolving PEO at $1.5 \% w / v$ and SA at $3 \% \mathrm{w} / \mathrm{v}$. Both spinning solutions were prepared at room temperature under stirring for $24 \mathrm{~h}$ to ensure their homogeneity. The polymer solutions were electrospun from $10 \mathrm{~mL}$ disposable syringes fitted with 23G tip-ground-toflat needles. The syringes were mounted on two Harvard PHD 2000 programmable syringe pumps (Harvard Apparatus, Holliston, MA, USA), which were positioned horizontally on an antiparallel setup to ensure the homogeneous blending of the fibers. Electrospinning was performed using a $\gamma$-High Voltage Research DC power supply generator with a maximum voltage of $50 \mathrm{kV}$ (Gamma High Voltage Research, Ormond Beach, FL, USA). The applied voltage was fixed at $25 \mathrm{kV}$. For the CA/PHBE solution, the tip-to-collector distance was fixed at $10 \mathrm{~cm}$, whereas for the PEO/SA solution, the distance was fixed at $20 \mathrm{~cm}$. The CA/PHBE solution feeding rate was fixed at $2 \mathrm{~mL} / \mathrm{h}$, while the PEO/SA solution feeding rate was adjusted at $0.5 \mathrm{~mL} / \mathrm{h}$, resulting in a $4: 1(w / w)$ blending ratio of CA/PHBE fibers to PEO/SA fibers, with a $16.5 \% w / w$ concentration of PHBE in the fabricated matrices. The produced nanofibers were collected on an RC-6000 (NaBond Technologies, Hong Kong) rotating drum collector wrapped with aluminum foil, at a rotation speed of $400 \mathrm{rpm}$. Temperature and relative humidity were $20 \pm 2{ }^{\circ} \mathrm{C}$ and $60 \pm 5 \%$, respectively. 


\subsection{Characterization of the Micro/Nanofibrous Patch}

A desktop PhenomWorld scanning electron microscope (Thermo Fischer Scientific, Waltham, MA, USA) with a charge reduction sample holder and tungsten filament $(10 \mathrm{kV})$ was used for the morphological characterization of the micro/nanofibers of the PHBE patch. To determine the average diameter of the fibers, the diameters of 100 fibers from each SEM image were measured in the embedded image analysis software (Phenom Pro Suite/Fibermetric). TGA analysis was conducted using a TA Thermogravimetric Analyzer (TGA 55, TA Instruments, New Castle, DE, USA) at a $10^{\circ} \mathrm{C} / \mathrm{min}$ heating rate from 40 to $600{ }^{\circ} \mathrm{C}$ under a $25 \mathrm{~mL} / \mathrm{min}$ nitrogen flow. Sample weight, sample temperature, and heat flow were recorded continuously. DSC analysis was performed using a TA Thermal Analyzer (Discovery DSC 25, TA instruments, New Castle, DE, USA). Samples of 6-7 mg sealed in aluminum pans were heated from 40 to $300{ }^{\circ} \mathrm{C}$ at a constant rate of $10^{\circ} \mathrm{C} / \mathrm{min}$ under a $25 \mathrm{~mL} / \mathrm{min}$ nitrogen flow.

\subsection{Study Design and Patient Selection}

All performed procedures were carried out in accordance with the Good Clinical Practice (GCP) guidelines established by the Directive 2001/20/EC, the Federal Code of Users of USA (21 CFR Part 312), and the International Conference on Harmonization (ICH). The study was conducted in accordance with the principles of the Declaration of Helsinki (Directive 2001/83/EC; ICH Issue E9 1996; Directive 2001/20/EC; Directive 2002/98/EC; Directive 2003/63/EC; ICH E (6) R1; 21 CFR Part 312; WHO 2008).

The volunteers were selected among the Radiotherapy Oncology Department patients of Andreas Syggros Hospital from November 2019 to February 2020. Eligible patients were adults with histologically confirmed NMSC before receiving radiation therapy. NMSC was located in the scalp, nose, lip, forehead, cheek, alar nasal sulcus, and nail. The exclusion criteria were pregnancy, breastfeeding, concomitant chemotherapy, immunosuppressive treatment, previous radiotherapy to the treated area, and patients with other autoimmune skin diseases, including atopic dermatitis, psoriasis, and ichthyosis.

This was an open-label 2-treatment clinical research trial comparing the efficacy of a new PHBE patch versus the reference cream. Twelve patients were selected and randomly assigned to 2 groups, applying either a PHBE patch or a reference medical cream product daily. All patients were patch tested for hypersensitivity to the PHBE patch and the reference cream's components.

\subsection{Radiotherapy Schedules}

The patients received local conventional radiotherapy (CRT) of 250 cGy in 23 fractions to a total dose of $5750 \mathrm{cGy} 5$ times a week with slight modifications to schema therapy depending on the case. The radiation energy was generated by orthovoltage $\mathrm{X}$-rays (Xstrahl 200, Walsall, UK).

The patients were instructed to apply to the irradiated area either a PHBE patch for $24 \mathrm{~h}$ every day or a thin layer of the reference cream twice a day during the radiotherapy period and for 1 month after its completion.

\subsection{Clinical Assessment}

All enrolled patients completed the study. Their mean age was 80 years; $75 \%$ were men and $25 \%$ were women. Among the patients, $50 \%$ had BCC, $25 \%$ had SCC, and $25 \%$ had BSC. Among all patients, $83.3 \%$ were surgically treated before receiving RT; $58.3 \%$ had primary and $25 \%$ had recurrent NMSC. Half of the patients received the micro/nanofibrous patch loaded with $P$. halepensis bark extract and the other half of the patients received the commercially available medical cream (reference product).

For all patients, a full medical history and demographic data, including age, body mass index (BMI), phototype (Fitzpatrick skin type), medical diseases, family history, sun exposure, and smoking, were recorded (Table 1). 
Table 1. Characteristics of the patients at baseline.

\begin{tabular}{|c|c|c|c|}
\hline Characteristics of Patients & $\begin{array}{l}\text { PHBE Patch Group } \\
(N=6)\end{array}$ & $\begin{array}{l}\text { Reference Product Group } \\
\qquad(N=6)\end{array}$ & $\begin{array}{l}\text { Total Patients } \\
\quad(N=12)\end{array}$ \\
\hline \multicolumn{4}{|c|}{ Demographics } \\
\hline Median age (interquartile range)_-year & $86(80-93)$ & $75(51-90)$ & $80(51-93)$ \\
\hline \multicolumn{4}{|l|}{ Gender-\% } \\
\hline Male & 66.7 & 83.3 & 75.0 \\
\hline Female & 33.3 & 16.7 & 25.0 \\
\hline \multicolumn{4}{|l|}{ Body mass index-\% } \\
\hline$>25$ (overweight) & 33.3 & 50 & 41.7 \\
\hline$<25$ (healthy weight) & 66.7 & 50 & 58.3 \\
\hline \multicolumn{4}{|l|}{ Fitzpatrick skin type-\% $\%$} \\
\hline I & 16.7 & 33.3 & 25.0 \\
\hline II & 50.0 & 33.3 & 41.7 \\
\hline III & 33.3 & 33.3 & 33.3 \\
\hline Unprotected sun exposure-\% & 100.0 & 83.3 & 91.7 \\
\hline Current Smoker-\% & 0.0 & 16.7 & 8.3 \\
\hline \multicolumn{4}{|c|}{ Characteristics of non-melanoma skin cancer (NMSC) } \\
\hline Cancer type-\% & & & \\
\hline Basal cell carcinoma (BCC) & 50.0 & 50.0 & 50.0 \\
\hline Squamous cell carcinoma (SCC) & 33.3 & 16.7 & 25.0 \\
\hline Basosquamous carcinoma (BSC) & 16.7 & 33.3 & 25.0 \\
\hline \multicolumn{4}{|l|}{ Tumor size $\left(\mathrm{cm}^{2}\right) \_\%$} \\
\hline$>20$ & 50.0 & 50.0 & 50.0 \\
\hline$<20$ & 50.0 & 50.0 & 50.0 \\
\hline Primary-\% & 83.3 & 50.0 & 66.7 \\
\hline Recurring-\% & 16.7 & 50.0 & 33.3 \\
\hline Surgery-\% & 100.0 & 66.7 & 83.3 \\
\hline \multicolumn{4}{|c|}{ Radiation therapy (RT) } \\
\hline \multicolumn{4}{|l|}{ Total dose (cGy)_\% } \\
\hline 5750 & 50.0 & 16.7 & 33.3 \\
\hline 5500 & 33.3 & 66.7 & 50.0 \\
\hline 4800 & 16.7 & 16.7 & 16.7 \\
\hline \multicolumn{4}{|l|}{ Fraction dose (cGy)—\% } \\
\hline 250 & 66.7 & 50.0 & 58.3 \\
\hline $200 / 400^{1}$ & 16.7 & 0.0 & 8.3 \\
\hline $250 / 300^{1}$ & 16.7 & 16.7 & 16.7 \\
\hline $250 / 308^{1}$ & 0.0 & 16.7 & 8.3 \\
\hline $300 / 400^{1}$ & 0.0 & 16.7 & 8.3 \\
\hline \multicolumn{4}{|l|}{ Fractions-\% } \\
\hline 15 & 0.0 & 16.7 & 8.3 \\
\hline 22 & 33.3 & 66.7 & 50.0 \\
\hline 23 & 66.7 & 16.7 & 41.7 \\
\hline
\end{tabular}

\footnotetext{
${ }^{1}$ Combination of fraction doses.
}

The most important diagnostic criteria for successful prophylaxis and treatment of acute radiodermatitis included clinical estimation and photo-documentation.

Radiation dermatitis on the irradiated skin was assessed according to the Radiation Therapy Oncology Group (RTOG) Common Terminology Criteria for Adverse Events (CTCAE) version 4.0 [16] during Days 7, 14, 21, and 28, and 1 month after RT (Day 60).

Skin inflammation was recorded before RT (Day 0), during Days 7, 14, 21, and 28, and 1 month after RT (Day 60). Skin images were acquired using a Nikon D5100 digital camera 
(Nikon, Tokyo, Japan) equipped with an AF-S Micro Nikkor $60 \mathrm{~mm}$ f/2.8 G ED lens (Nikon, Tokyo, Japan), which was at a distance of $33 \mathrm{~cm}$ perpendicular to the skin.

Radiation-associated symptoms of pain and itching were reported by patients during Days 7, 14, 21, and 28, and 1 month after RT (Day 60) using a visual analogue scale (VAS) (10 $\mathrm{cm}$ in length; $0=$ no symptoms, $10=$ highly intense symptoms $)$.

\subsection{Skin Analysis}

The skin was evaluated by an Antera 3D camera (Miravex, Dublin, Ireland) before RT (Day 0), during Days 7, 14, 21, and 28, and 1 month after RT (Day 60). Hemoglobin concentration and skin texture were assessed with Antera 3D software (Miravex, Dublin, Ireland).

\subsection{Measurements of the Skin's Biophysical Parameters}

Skin parameters, including hydration, TEWL, erythema, and melanin, were evaluated using non-invasive biophysical methods before RT (Day 0), during Days 7, 14, 21, and 28, and 1 month after RT (Day 60). Hydration was measured using a Corneometer CM 820 (Courage + Khazaka electronic GmbH, Köln, Germany) through changes in the dielectric constant. The indications were recorded in arbitrary units. The barrier function of the skin (TEWL) was evaluated using a Tewameter TM 210 (Courage + Khazaka electronic $\mathrm{GmbH}$, Köln, Germany) by measuring the density gradient of the water evaporation from the skin. The estimation was based on the mean value of the flux density of water (in $\mathrm{g} / \mathrm{m}^{2} / \mathrm{h}$ ), which was obtained $1 \mathrm{~min}$ after the beginning of the measurement. Erythema and melanin were calculated using a Mexameter MX 18 (Courage + Khazaka electronic GmbH, Köln, Germany) by measuring absorption/reflection at 3 different light wavelengths. The indications were recorded in arbitrary units. Before each measurement, the treated area was cleaned with $0.9 \%$ sodium chloride solution and wiped with sterile gauze.

\subsection{Patient Self-Report}

The two therapeutic interventions were evaluated by patients using a questionnaire 1 month after RT (Day 60). The color, texture, applicability, ease of use, absence of irritation, and overall evaluation of the PHBE patch and the reference product were assessed using a standardized scale from 0 (maximum negative impact) to 5 (maximum positive impact).

\subsection{Statistical Analysis}

Statistical analyses were performed using the Statistical Package for the Social Sciences (SPSS version 25, IBM, Chicago, IL, USA). Data were described using the mean \pm standard deviation (SD) and proportions. A normality test was conducted to determine whether the sample data had been drawn from a normally distributed population based on KolmogorovSmirnov and Shapiro-Wilk criteria. Either an independent sample $t$-test for parametric measurements or the Mann-Whitney U-test for non-parametric measurements was used to calculate differences between the therapeutic interventions. Treatment values were compared with the pretreatment baseline by the parametric method of a paired $t$-test or the non-parametric Wilcoxon-signed rank test method in both treatments; $p$-values of $<0.05$ were considered statistically significant and are indicated by the $\left.{ }^{*}\right)$ symbol for $p<0.05$, $\left.{ }^{* *}\right)$ for $\left.p<0.01,{ }^{* * *}\right)$ for $p<0.001$, and $\left(^{* * *}\right)$ for $p<0.0001$.

\section{Results and Discussion}

Polymeric micro/nanofibers loaded with PHBE were obtained as a non-woven patch and evaluated for their ability to prevent acute radiodermatitis in patients with NMSC undergoing radiotherapy. Based on our previous findings [24], SA, PEO, and CA polymers were selected for the fabrication of the PHBE micro/nanofibrous patches, since they are considered to be non-toxic biopolymers of choice for many wound dressings and other biomedical applications [47-49].

The simultaneous electrospinning of the CA/PHBE and PEO/SA spinning solutions on the same rotating drum collector through an antiparallel electrospinning setup ensured 
the successful blending of the fibers in the patches. By fine-tuning the electrospinning parameters [26], a uniform fibrous mat was obtained with bead-free fibers. Analysis of the SEM images (Figure 1) revealed blended fibers of ribbon-like and cylindrical morphologies with size diameters ranging from $289 \mathrm{~nm}$ to $2.4 \mu \mathrm{m}$ and an average diameter size of $1.1 \pm 0.22 \mu \mathrm{m}$.
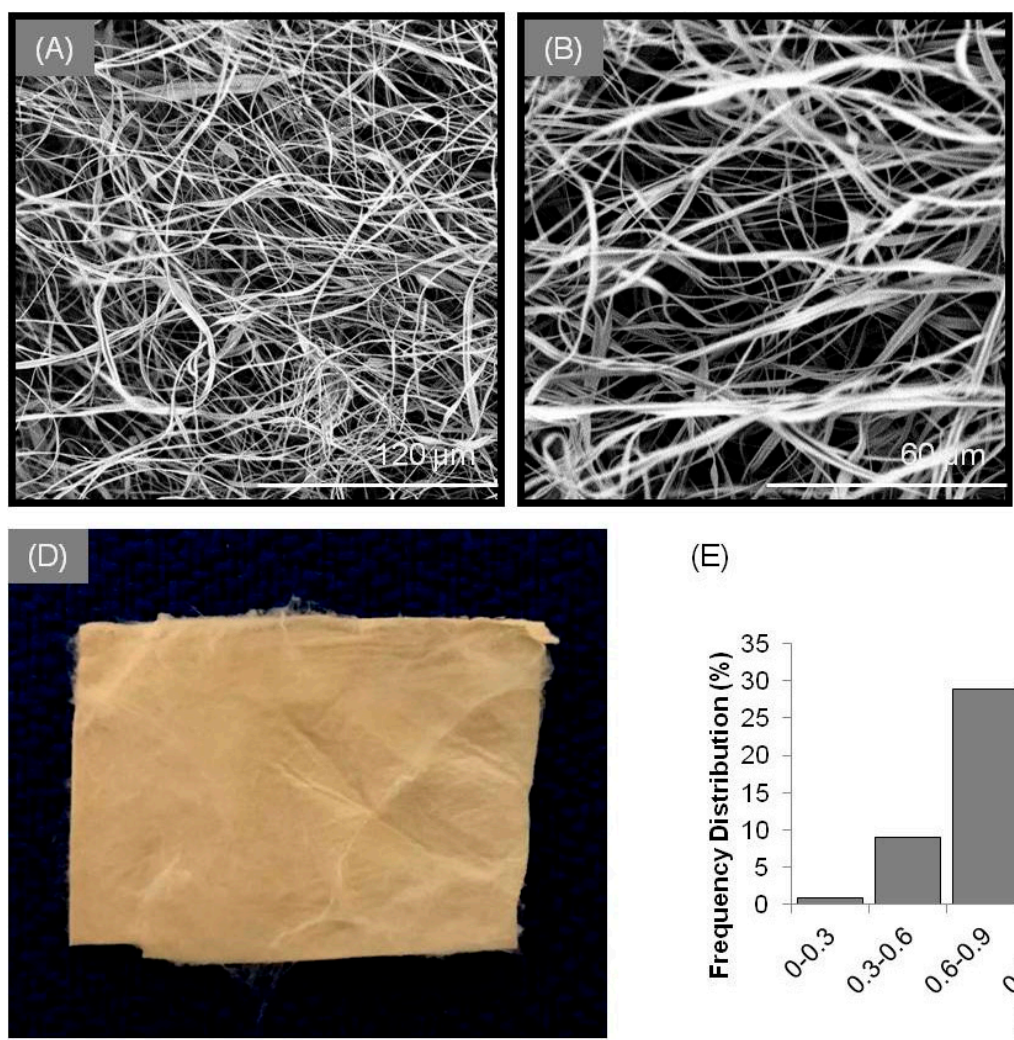

(E)

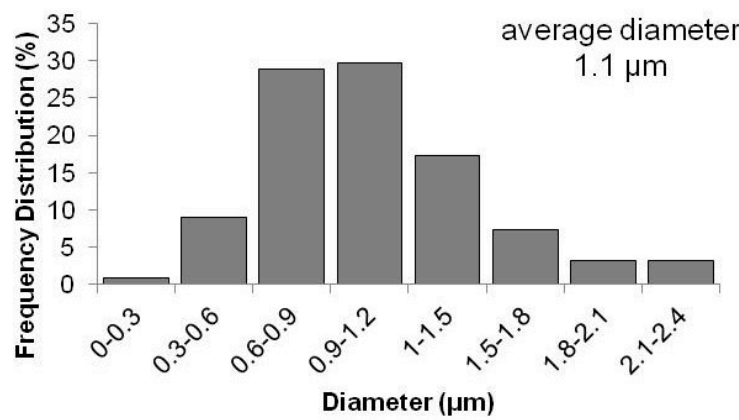

Figure 1. SEM images of the PHBE micro/nanofibrous patch at (A) $1000 \times$, (B) $2000 \times$, and (C) $3000 \times$ magnification. (D) Image of a PHBE micro/nanofibrous patch. (E) Average diameter distribution histogram of fibers in PHBE dressings.

The fabricated PHBE micro/nanofibers were physicochemically characterized by TGA and DSC analyses. In the TGA thermograms (Figure 2A), all starting materials (PHBE, CA, PEO, and SA powders) and the electrospun PHBE micro/nanofibrous patch recorded a single degradation step. PHBE started to decompose at $251{ }^{\circ} \mathrm{C}$, the degradation step of CA was recorded at $322{ }^{\circ} \mathrm{C}$, PEO decomposition initiated at $352{ }^{\circ} \mathrm{C}$, and SA showed a decomposition step at $216^{\circ} \mathrm{C}$. The initial slight mass loss in the case of PHBE and SA is attributed to the volatilization of moisture and hydrogen-bound water. The PHBE fibers showed a broad thermogravimetric curve with a slight mass loss due to moisture volatilization up to their decomposition step at $272^{\circ} \mathrm{C}$. The different thermal behavior of the PHBE micro/nanofibrous patch was also evident in the derivative thermogravimetry (DTG) thermograms (Figure 2B). The maximum decomposition rate was recorded at $275^{\circ} \mathrm{C}$ for PHBE, $355^{\circ} \mathrm{C}$ for $\mathrm{CA}, 385^{\circ} \mathrm{C}$ for $\mathrm{PEO}, 240{ }^{\circ} \mathrm{C}$ for SA, and at $338^{\circ} \mathrm{C}$ for the PHBE fibers.

In the DSC thermograms (Figure $2 \mathrm{C}$ ), the broad endotherms below $100^{\circ} \mathrm{C}$ recorded for PHBE, CA, and SA are attributed to dehydration phenomena. CA and PEO showed melting endothermic peaks at $232{ }^{\circ} \mathrm{C}$ and $70{ }^{\circ} \mathrm{C}$, respectively, whereas the exothermic bands of SA and PHBE at approximately $250{ }^{\circ} \mathrm{C}$ are associated with degradation events. The PHBE micro/nanofibrous patch showed a broad dehydration endotherm between the ambient temperature and $100{ }^{\circ} \mathrm{C}$, followed by an endothermic melting band at $228^{\circ} \mathrm{C}$ and a broad degradation exotherm over $250^{\circ} \mathrm{C}$, revealing a different thermal profile arising from the synergistic degradation events of the combined raw materials. 
(A)

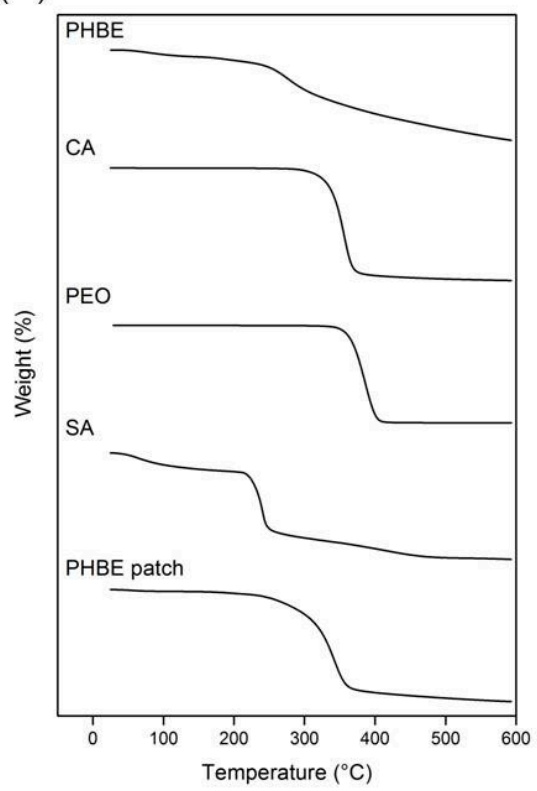

(B)

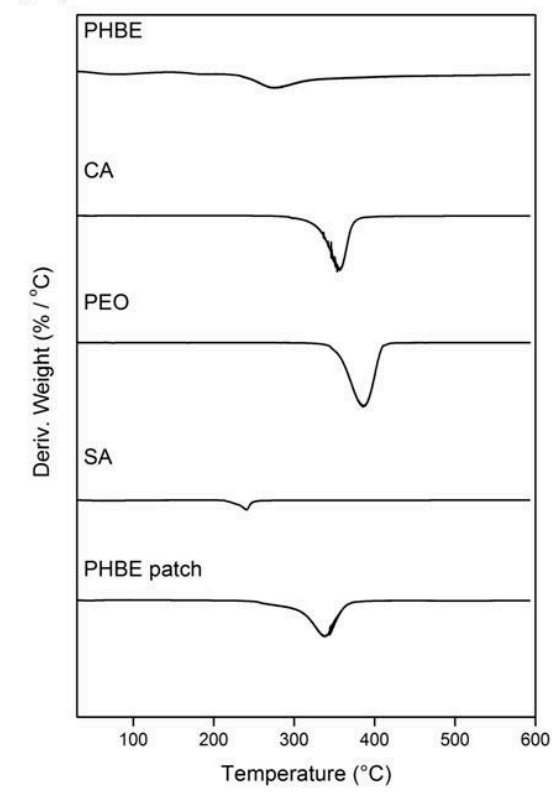

(C)

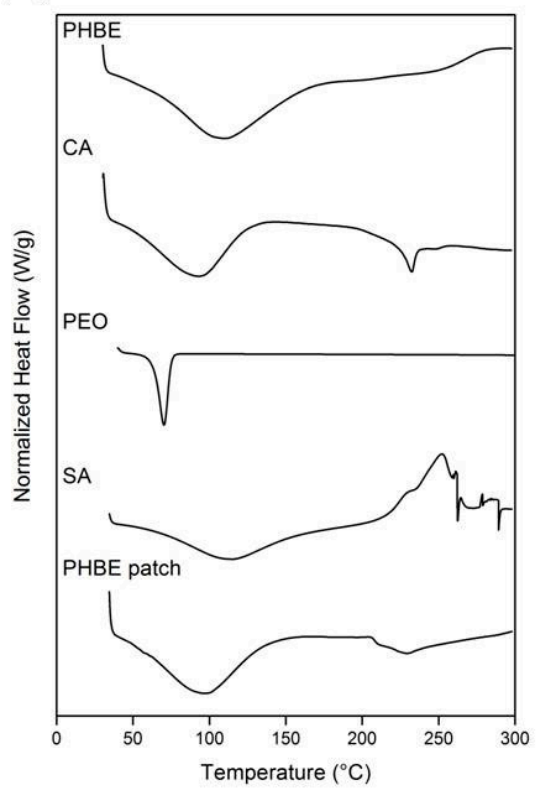

Figure 2. (A) TGA, (B) DTG and (C) DSC thermograms of the raw materials and the electrospun PHBE micro/nanofibrous patch.

According to the characteristics of the patients (Table 1), there were no significant differences between the group of patients receiving the PHBE patch therapy (PHBE patch patients) and the group of patients receiving the reference cream therapy (reference cream patients) concerning the demographics, tumor characteristics, and RT doses $(p>0.05)$ of the patients (Table 2).

Table 2. $p$-values for patients' baseline characteristics. Values lower than or equal to $5 \%(p \leq 0.05)$ indicate a statistical difference.

\begin{tabular}{cr}
\hline Characteristics of Patients & $p$-Value \\
\hline & Demographics \\
Age & 0.394 \\
Gender & 0.699 \\
Body mass index & 0.132 \\
Fitzpatrick skin type & 0.818 \\
Sun exposure & 0.699 \\
Smoking & 0.699 \\
\hline Characteristics of non-melanoma skin cancer (NMSC) \\
Cancer type & 0.818 \\
Tumor size & 0.394 \\
Primary or recurring & 0.394 \\
Surgery or not & 0.394 \\
\hline & Radiation therapy (RT) \\
Total dose & 0.310 \\
Fraction dose & 0.394 \\
Fractions & 0.132 \\
\hline
\end{tabular}

The clinical estimation of acute radiodermatitis based on RTOG criteria is presented in Figure 3. In PHBE patch patients, acute radiodermatitis onset was observed after 21 days and reached a maximum Grade 1 on the RTOG scale, while in the patients using the reference cream, the onset was observed after 7 days, reaching a maximum Grade 3. More specifically, in the first 2 weeks of RT, no radiodermatitis was observed in the PHBE patch patients, while all reference cream patients had Grade 1-2 acute radiodermatitis. In the next 2 weeks, the PHBE patch patients had Grade 1-2 radiodermatitis, while the reference 
cream patients had Grades 2-3. One month after completion of RT (Day 60), only PHBE patch patients displayed total skin recovery without signs of radiodermatitis, while $50 \%$ of the reference cream patients had Grade 1 acute radiodermatitis, 17\% had Grade 2, and 33\% had Grade 3. The acute radiodermatitis incidence was significantly different between the two interventions throughout the whole study period (Day 7, $p=0.015$; Day 14, $p=0.002$; Day 21, $p=0.002$; Day 28, $p=0.009$; Day 60, $p=0.004)$.

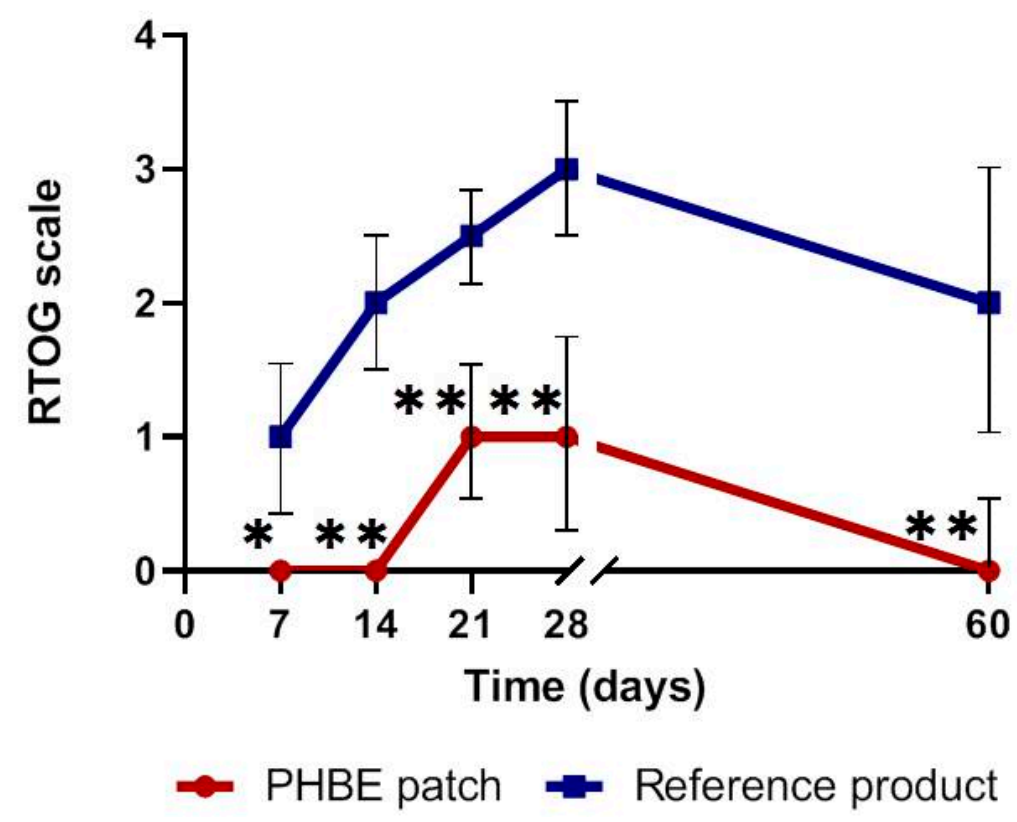

Figure 3. Clinical estimation of acute radiodermatitis based on RTOG criteria, before radiation therapy (RT) (Day 0); during Days 7, 14, 21, and 28; and 1 month after RT (Day 60). Significant differences were observed between the two interventions throughout the treatment period $\left({ }^{*} p<0.05\right.$, ** $p<0.01$ ). Total skin recovery was observed in the PHBE patch patients 1 month after RT (Day 60).

The above results were confirmed by photo-documentation (Figures 4, S2 and S3). Clinical evaluation showed that the PHBE patch significantly soothed inflamed skin, preventing and treating acute radiodermatitis. No clinical signs of acute radiodermatitis were observed 1 month after completion of RT (Day 60) in the PHBE patch patients (Figure 4A,B). Only one patient developed irritant contact dermatitis due to the medical tape, which was treated by application of a PHBE patch on the irritated area (Figure 4A, Days 21 and 28). In the case of the reference cream, extended inflammation was observed for all patients that suffered mechanical skin injuries due to the difficulty in cream removal (Figure 4C,D).

Mean pain and itching were significantly lower for patients applying the PHBE patch in comparison with those applying the reference cream. No pain or itching were observed 1 month after RT (Day 60) only in PHBE patch patients (Figure 5). In total, 73\% of patients using the PHBE patch completed the study pain-free, while all patients using the reference cream suffered from pain. The mean pain scores were higher in the reference cream patients. Significant differences were recorded between the two interventions (Figure 5A) (Day 21, $p=0.009$; Day 28, $p=0.03$ ). No itching was observed 1 month after completion of RT (Day 60) for patients using the PHBE patch, while all patients using the reference cream showed persistent itching. The mean itching scores were higher in the reference cream patients. Significant differences were recorded between the two interventions (Figure 5B) (Day 21, $p=0.004$; Day 28, $p=0.004$; Day 60, $p=0.002$ ). 


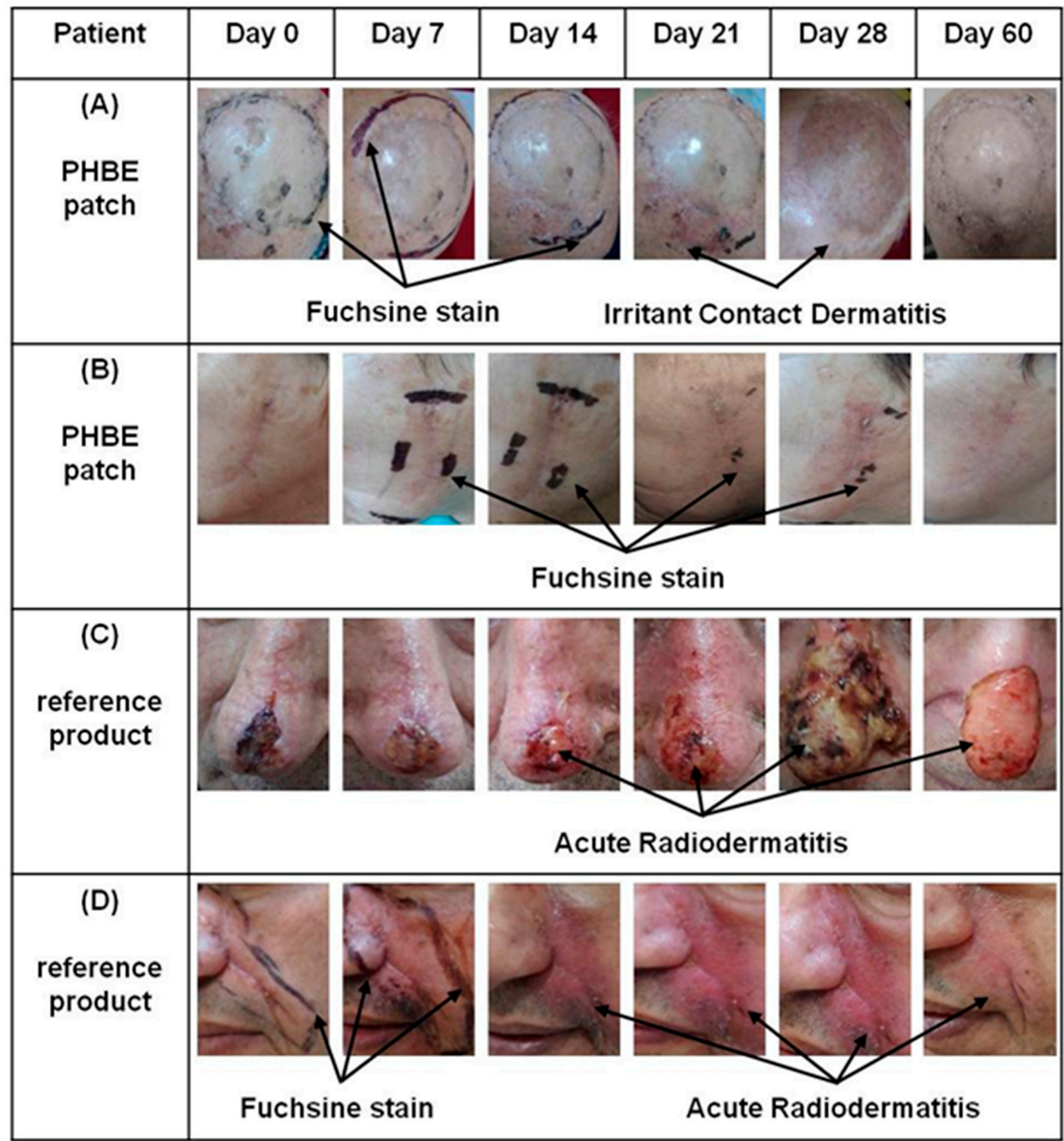

Figure 4. Representative images of (A) an 81-year-old male patient treating a scalp transplant with a PHBE patch, (B) an 80-year-old female patient treating a cheek with a PHBE patch, (C) an 82-year-old male patient treating the nose and nasal tip with the reference product, and (D) a 58-year-old male patient treating the cheek and alar nasal sulcus with the reference product before RT (Day 0); during Days 7, 14, 21, and 28; and 1 month after RT (Day 60). In contrast to the reference cream, the PHBE patch demonstrated significant anti-inflammatory efficacy. 
(A) Pain

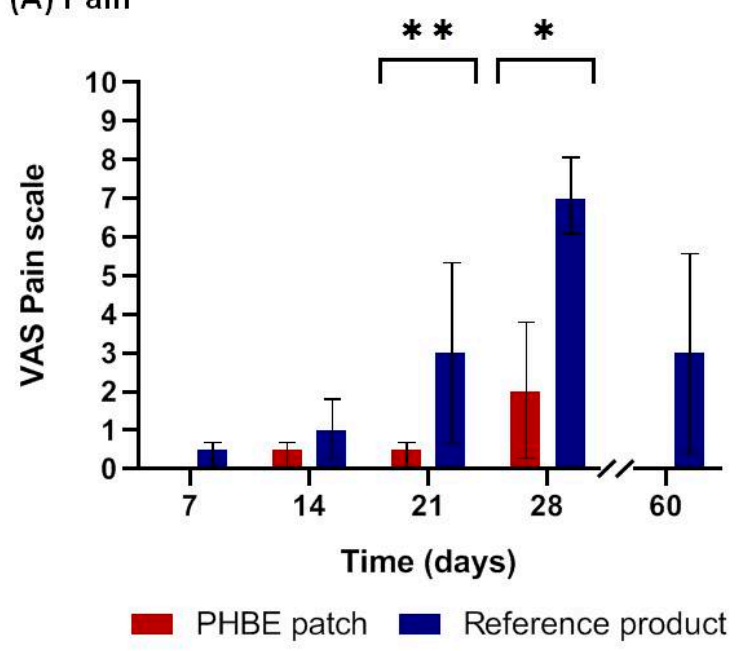

(B) Itching

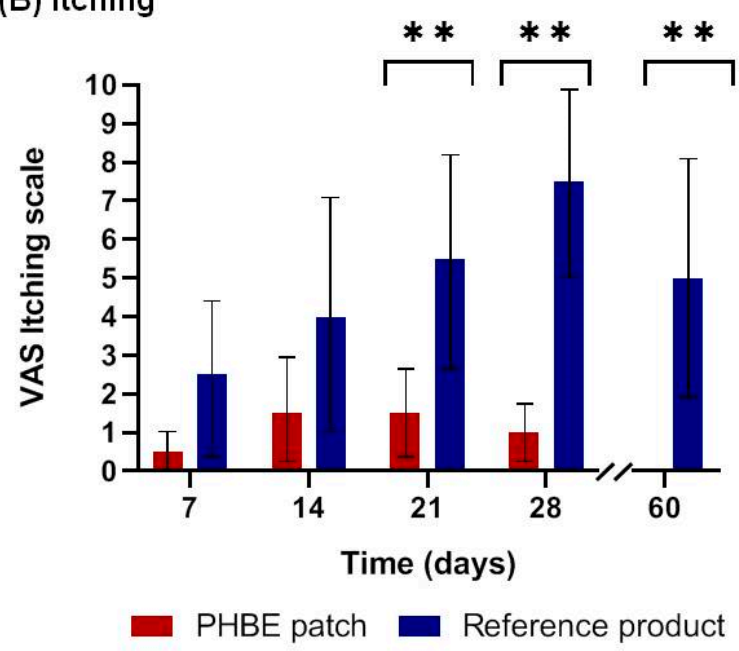

Figure 5. Patient self-report of (A) pain and (B) itching based on a visual analog scale (VAS) before radiation therapy (RT) (Day 0); during Days 7, 14, 21, and 28; and 1 month after RT (Day 60). Significant differences were observed between the two interventions throughout the treatment period $\left({ }^{*} p<0.05,{ }^{* *} p<0.01\right)$. In contrast to the reference cream patients, no pain or itching was observed in the PHBE patch patients 1 month after RT (Day 60).

According to the images analyzed with Antera 3D software (Figures 4, S4 and S5), the PHBE patch exhibited remarkable anti-inflammatory activity on radiation-exposed skin and contributed to the recovery process 1 month after completion of RT (Day 60). The reference cream showed rapid onset, progression, and failure in treating acute radiodermatitis.

\begin{tabular}{|c|c|c|c|c|c|c|}
\hline $\begin{array}{c}\text { Patient } \\
\begin{array}{c}\text { PHBE } \\
\text { patch }\end{array}\end{array}$ & Day 0 & Day 7 & Day 14 & Day 21 & Day 28 & Day 60 \\
\hline $\begin{array}{c}\text { (A) } \\
\text { (B) } \\
\text { reference } \\
\text { product }\end{array}$ & Fuchsine stain & & & & & \\
\end{tabular}

Figure 6. Representative Antera 3D images of (A) an 87-year-old female patient treating the alar nasal sulcus and upper lip area with a PHBE patch and (B) an 85-year-old female patient treating the alar nasal sulcus and upper lip area with the reference product before radiation (RT) (Day 0); during Days 7, 14, 21, and 28; and 1 month after RT (Day 60). In contrast to the reference cream, the PHBE patch demonstrated significant anti-inflammatory efficacy and skin recovery 1 month after RT (Day 60). 
Mean hemoglobin concentration and skin texture value increase when inflammation intensity escalates. A lower rate of hemoglobin concentration was observed throughout the study period for patients using the PHBE patch in comparison with the patients using the reference cream. One month after completion of RT (Day 60), hemoglobin concentration returned to the initial levels for the PHBE patch patients, while it remained increased for patients using the reference cream. Significant differences were recorded between the two interventions throughout the treatment period (Figure 7A) (Day 0, $p=0.016$; Day 7, $p=0.006$; Day 14, $p=0.013$; Day 21, $p=0.025$; Day 28, $p=0.047$; Day 60, $p=0.002$ ). A significant difference was observed between Day 0 and Day 60 in the reference cream patients $(p=0.002)$.

(A) Haemoglobin

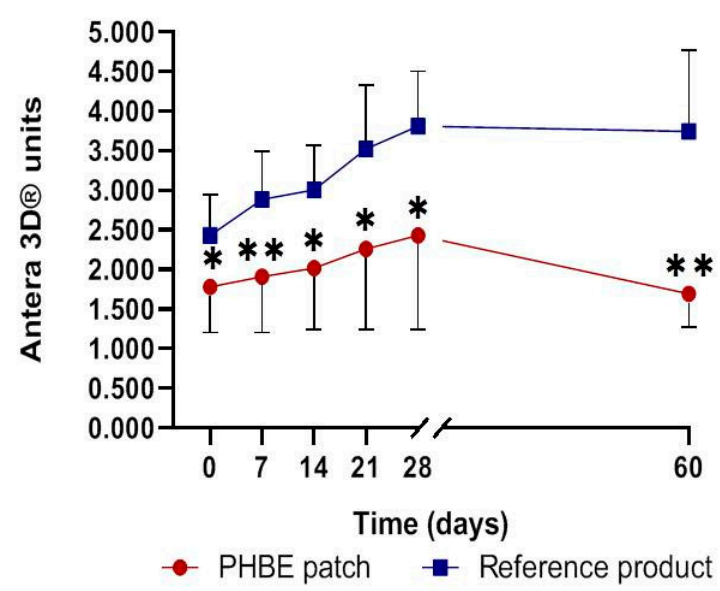

\section{(B) Skin texture}

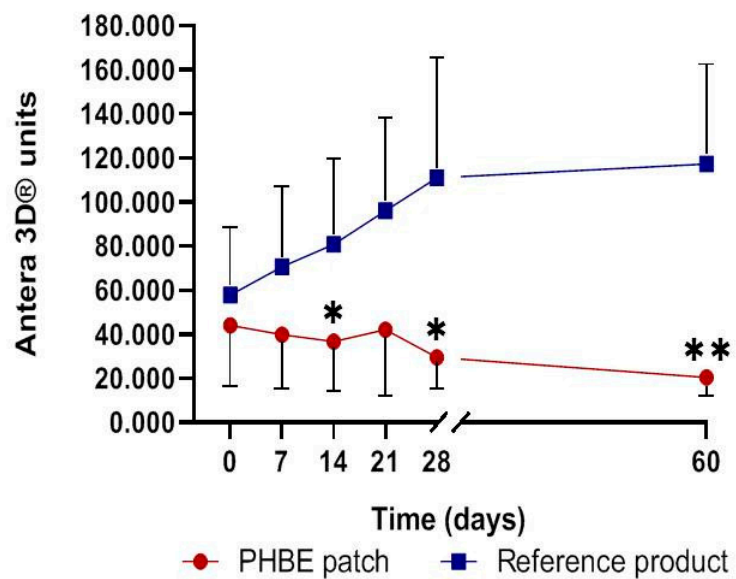

Figure 7. (A) Hemoglobin concentration and (B) skin texture value before radiation therapy (RT) (Day 0); during Days 7, 14, 21, and 28; and 1 month after RT (Day 60). Significant differences were recorded between the two interventions at most of the time points $\left({ }^{*} p<0.05,{ }^{* *} p<0.01\right)$. Hemoglobin concentration and skin texture value returned to the initial levels 1 month after RT (Day 60) in patients using the PHBE patch.

A lower value of skin texture was measured throughout the treatment period for patients using the PHBE patch in comparison with the patients using the reference cream. After Day 21, skin texture returned to the initial values for PHBE patch patients, while it increased for patients using the reference cream. Significant differences were recorded between the two interventions throughout the treatment period (Figure 7B) (Day 14, $p=0.045$; Day 28, $p=0.027$; Day 60, $p=0.004)$. A significant difference was observed between Day 0 and Day 60 in both intervention patients (PHBE patch, $p=0.037$; reference creams $p=0.005)$.

Hydration, TEWL, and erythema, as well as melanin to a lesser degree, are directly associated with inflammation severity [27]. Upon skin inflammation, TEWL, erythema, and melanin levels increase, whereas hydration decreases. All measurements of biophysical skin parameters showed that the PHBE patch was able to re-establish a normal skin barrier and return the stratum corneum to its physiological state 1 month after RT (Day 60) (Figure 8).

The PHBE patch maintained the hydration levels of the stratum corneum at normal values, while the application of the reference cream resulted in lower hydration of the skin. However, no significant difference was observed between the two interventions at any time point (Figure 8A).

Before RT (Day 0), the skin barrier function was similar in the two interventions. From Day 7 to Day 60, TEWL remained almost stable for the patients using the PHBE patch, while it continuously increased for those using the reference cream. Significant differences were observed between the two interventions at most of the time points (Figure 8B) (Day 7, $p=0.004$; Day 14, $p=0.004$; Day 21, $p=0.002$; Day 28, $p=0.004$; Day 60, $p=0.002$ ). A 
significant difference between Day 0 and Day 60 was recorded for the patients using the reference product $(p=0.043)$.

(A) Hydration

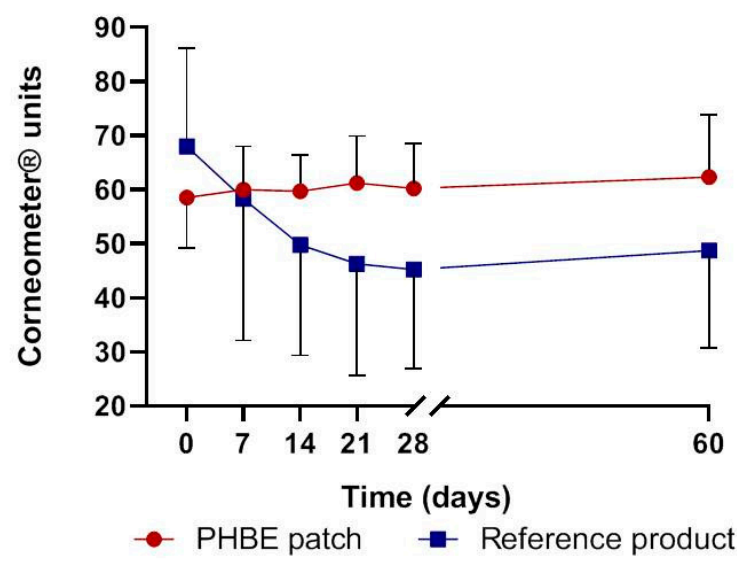

(C) Erythema

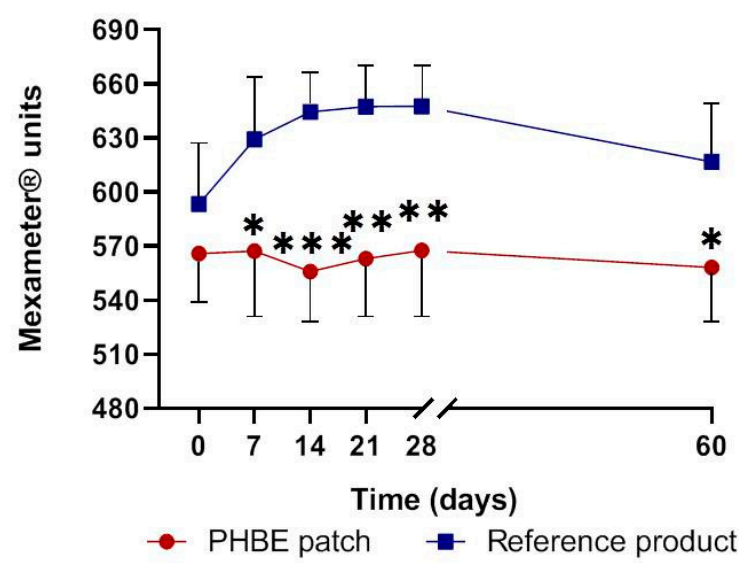

(B) TEWL

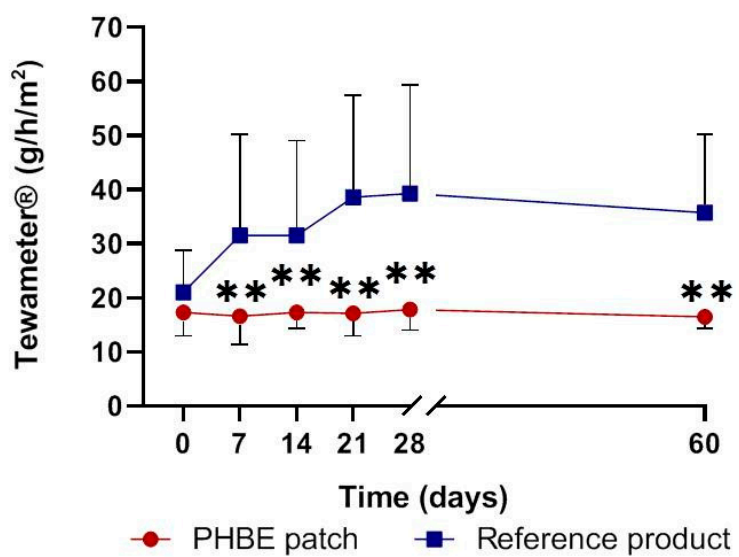

(D) Melanin

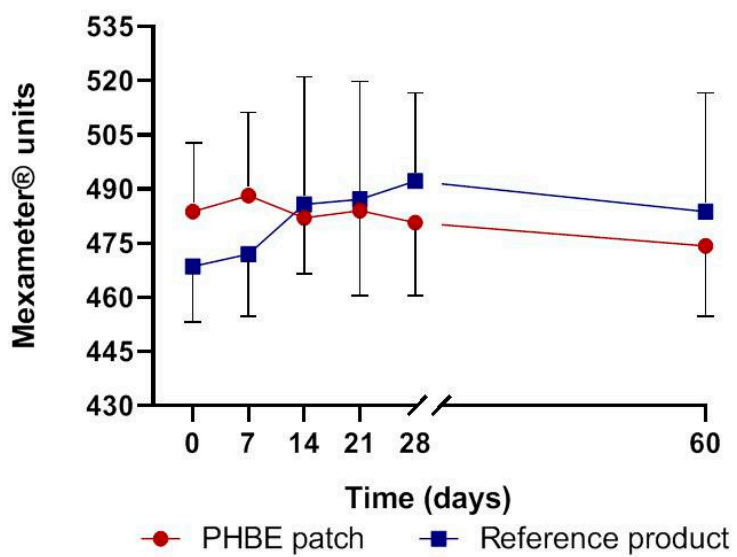

Figure 8. Evaluation of (A) hydration, (B) TEWL, (C) erythema, and (D) melanin, before radiation therapy (RT) (Day 0); during Days 7, 14, 21, and 28; and 1 month after RT (Day 60). Regarding TEWL and erythema, significant differences were recorded between the two interventions at most of the time points $\left({ }^{*} p<0.05,{ }^{* *} p<0.01,{ }^{* * *} p<0.001\right)$. All the biophysical skin parameters returned to the initial values 1 month after RT (Day 60) for the patients using the PHBE patch.

A lower value of erythema was observed throughout the study period for the PHBE patch patients compared with the patients using the reference cream. Significant differences were recorded between the two interventions for most of the time points (Figure 8C) (Day 7, $p=0.017$; Day 14, $p=0$; Day 21, $p=0.001$; Day 28, $p=0.003$; Day 60, $p=0.010$ ). Additionally, a significant difference was observed between Day 0 and Day 60 in the reference cream patients $(p<0.05, p=0.008)$.

Regarding melanin, no statistically significant variation was observed between the two interventions (Figure 8D).

All patients filled out a questionnaire in which they were asked to comment on their experience using the PHBE patch or the reference cream (Figure 9). A content analysis revealed that in terms of color, texture, applicability, ease of use, absence of irritation, and overall evaluation, the patients preferred the PHBE patch over the reference cream. Additionally, the PHBE patch scored highly on all intervention characteristics, except for the color (Figure 9). Significant differences were observed between the two interventions concerning all characteristics (color, $p=0.015$; texture, $p=0.004$; applicability, $p=0.002$; ease of use, $p=0.002$; absence of irritation, $p=0.002$; overall evaluation, $p=0.002$ ). 


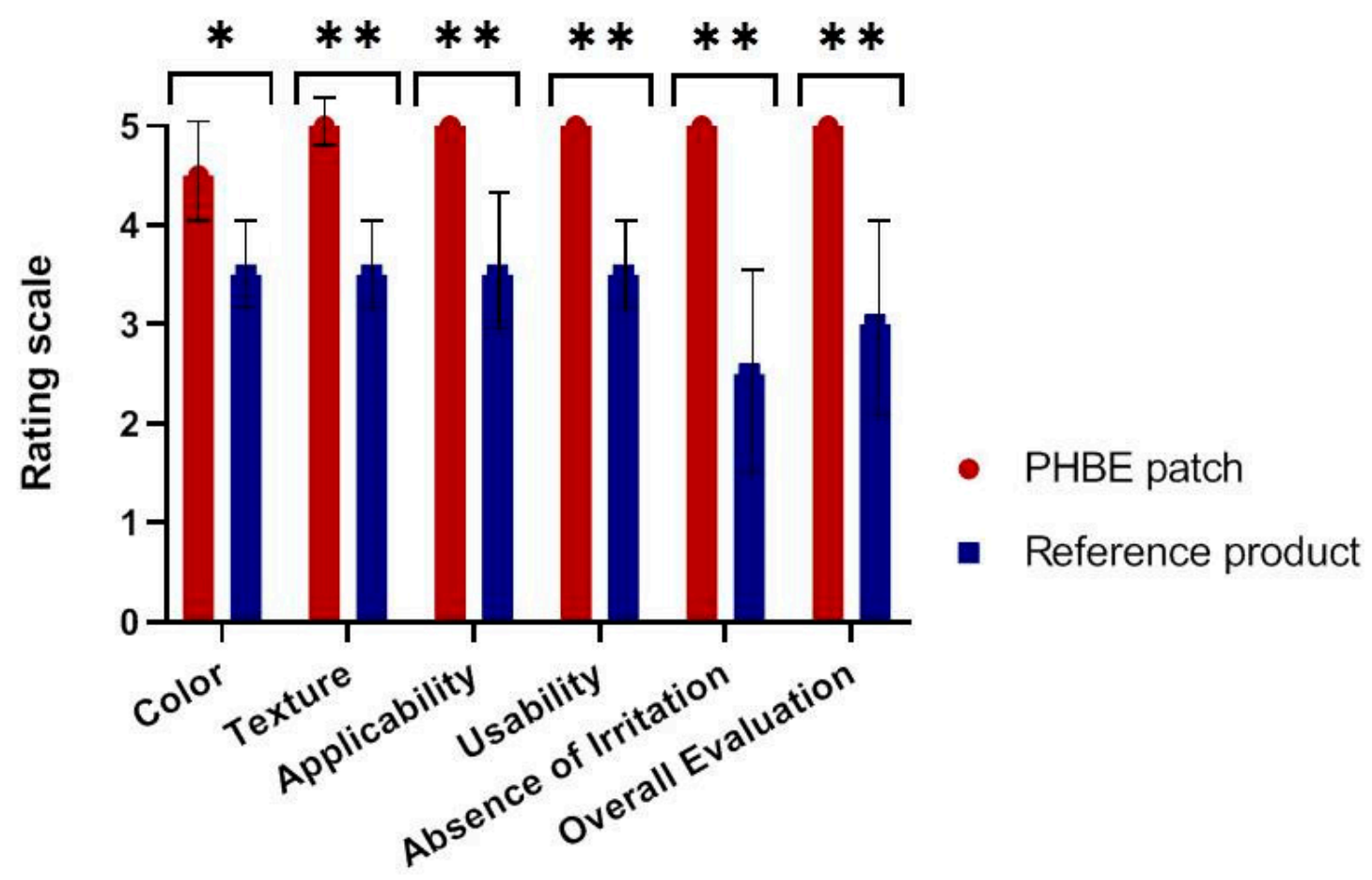

Figure 9. Patients' evaluation of the two interventions (PHBE patch and reference cream) based on their main characteristics (color, texture, applicability, ease of use, absence of irritation, and overall evaluation). Significant differences were observed between the two interventions $\left({ }^{*} p<0.05,{ }^{* *} p<0.01\right.$ ), with patients preferring the PHBE patch over the reference cream.

The obtained results are in accordance with recent research data on barrier-forming products in radiotherapy and corroborate the assumed principle of prophylactic superficial skin protection for the reduction or even prevention of radiation dermatitis [50-53]. The main limitation of the present clinical trial was the small sample size, while another limitation was the subjective scale (VAS) used for measuring pain and itching severity, which could not exclude patient bias. However, a uniform treatment site was attempted, without varied fractionation schedules and patient compliance with prophylactic interventions. Considering the promising results of this preliminary study, a clinical trial with a higher number of volunteer patients should be conducted.

\section{Conclusions}

In this study, the efficiency of an optimized PHBE micro/nanofibrous patch on preventing or treating acute radiodermatitis in NMSC patients undergoing radiotherapy was assessed in comparison with a commercially available reference cream. The topical application of the PHBE patch significantly contributed to prophylaxis and successful management of acute radiodermatitis throughout the treatment period. Significant beneficial effects were observed on the RTOG scale, TEWL, erythema, hemoglobin concentration, skin texture, and subjective itching and pain experience, while no statistically significant variation between the two interventions was observed for hydration and melanin. Moreover, 1 month after RT, the PHBE patch, in contrast to the reference cream, eliminated skin inflammation, restored the biophysical skin parameters to normal values, and reduced the discomfort of the patients. The PHBE patch was well accepted by all patients and proved statistically effective, without any adverse reaction reported, indicating that the PHBE patch is a safe prophylactic radiodermatitis treatment. Taking into account that numerous clinical studies on systemic and topical treatments have not yet succeeded in providing satisfactory prophylaxis for acute radiodermatitis, the effective application of bioactive micro/nanofibrous non-woven patches loaded with PHBE could offer great potential towards the development of a new generation of anti-inflammatory topical skincare dressings with tunable properties and controlled administration characteristics. 
Supplementary Materials: The following are available online at https: / www.mdpi.com/article/ 10.3390/cancers13112596/s1. Figure S1: Application of the PHBE patch on a representative patient enrolled in the study. Figures S2 and S3: Images of all patients treated with the PHBE patch and the reference product, respectively, during Days 7, 14, 21, and 28, and 1 month after RT (Day 60). Figures S4 and S5: Antera 3D images of all patients treated with the PHBE patch and the reference product, respectively, during Days 7, 14, 21, and 28, and 1 month after RT (Day 60).

Author Contributions: Conceptualization, E.I., V.R. and M.R.; methodology, A.K., S.K., A.T., N.K., A.E., P.P., A.S., V.K., P.D., A.V., E.I., V.R. and M.R.; formal analysis, A.K., S.K. and V.K.; investigation, A.K., S.K., A.T. and V.K.; resources, N.K., E.I., V.R. and M.R.; writing-original draft preparation, A.K. and S.K.; writing-review and editing, A.T., N.K., E.I., V.R. and M.R.; visualization, A.K., S.K., and V.K.; supervision, A.T., N.K., E.I., V.R. and M.R.; project administration, E.I., V.R. and M.R.; funding acquisition, E.I. and V.R. All authors have read and agreed to the published version of the manuscript.

Funding: This research was partially funded by the research projects MARINOVA (grant number 70/3/14684) and BioNP (grant number 70/3/14685). The authors thank the Special Account for Research Grants of the National and Kapodistrian University of Athens for funding to cover the publication costs.

Institutional Review Board Statement: The study was conducted according to the guidelines of the Declaration of Helsinki and approved by the Andreas Syggros Dermatological Hospital Scientific Committee (3343/6-11-2019).

Informed Consent Statement: Informed consent was obtained from all subjects involved in the study.

Data Availability Statement: The data presented in this study are available on request from the corresponding authors.

Acknowledgments: Access to the infrastructure obtained by the research project "Center for the study and sustainable exploitation of Marine Biological Resources" (CMBR, MIS 5002670) in the framework of the National Roadmap for Research Infrastructures is gratefully acknowledged.

Conflicts of Interest: The authors declare no conflict of interest. The funders had no role in the design of the study; in the collection, analyses, or interpretation of data; in the writing of the manuscript, or in the decision to publish the results.

\section{References}

1. Da Silva, E.S.; Tavares, R.; Paulitsch, F.D.S.; Zhang, L. Use of sunscreen and risk of melanoma and non-melanoma skin cancer: A systematic review and meta-analysis. Eur. J. Dermatol. EJD 2018, 28, 186-201. [CrossRef] [PubMed]

2. Linares, M.A.; Zakaria, A.; Nizran, P. Skin Cancer. Prim. Care Clin. Off. Pr. 2015, 42, 645-659. [CrossRef] [PubMed]

3. Marinho, S.A.; Lima, N.L.; Verli, F.D.; De Miranda, J.L. Basosquamous carcinoma: Histopathological features. Indian J. Dermatol. 2012, 57, 382-383. [CrossRef] [PubMed]

4. Liu-Smith, F.; Jia, J.; Zheng, Y. UV-Induced Molecular Signaling Differences in Melanoma and Non-melanoma Skin Cancer. Adv. Exp. Med. Biol. 2017, 996, 27-40. [CrossRef]

5. Madan, V.; Lear, J.T.; Szeimies, R.-M. Non-melanoma skin cancer. Lancet 2010, 375, 673-685. [CrossRef]

6. Miller, D.L.; Weinstock, M.A. Nonmelanoma skin cancer in the United States: Incidence. J. Am. Acad. Dermatol. 1994, 30, 774-778. [CrossRef]

7. Peris, K.; Fargnoli, M.C.; Garbe, C.; Kaufmann, R.; Bastholt, L.; Seguin, N.B.; Bataille, V.; Del Marmol, V.; Dummer, R.; Harwood, C.A.; et al. Diagnosis and treatment of basal cell carcinoma: European consensus-based interdisciplinary guidelines. Eur. J. Cancer 2019, 118, 10-34. [CrossRef]

8. Stratigos, A.J.; Garbe, C.; Dessinioti, C.; Lebbe, C.; Bataille, V.; Bastholt, L.; Dreno, B.; Fargnoli, M.C.; Forsea, A.M.; Frenard, C.; et al. European interdisciplinary guideline on invasive squamous cell carcinoma of the skin: Part 1. epidemiology, diagnostics and prevention. Eur. J. Cancer 2020, 128, 60-82. [CrossRef]

9. Verkouteren, J.; Ramdas, K.; Wakkee, M.; Nijsten, T. Epidemiology of basal cell carcinoma: Scholarly review. Br. J. Dermatol. 2017, 177, 359-372. [CrossRef]

10. Kallini, J.R.; Hamed, N.; Khachemoune, A. Squamous cell carcinoma of the skin: Epidemiology, classification, management, and novel trends. Int. J. Dermatol. 2014, 54, 130-140. [CrossRef]

11. Rong, Y.; Zuo, L.; Shang, L.; Bazan, J.G. Radiotherapy treatment for nonmelanoma skin cancer. Expert Rev. Anticancer. Ther. 2015, 15, 765-776. [CrossRef] [PubMed]

12. Bichakjian, C.K.; Olencki, T.; Aasi, S.Z.; Alam, M.; Andersen, J.S.; Berg, D.; Bowen, G.M.; Cheney, R.T.; Daniels, G.A.; Glass, L.F.; et al. Basal Cell Skin Cancer, Version 1.2016, NCCN Clinical Practice Guidelines in Oncology. J. Natl. Compr. Cancer Netw. 2016, 14, 574-597. [CrossRef] 
13. Bray, F.N.; Simmons, B.J.; Wolfson, A.H.; Nouri, K. Acute and Chronic Cutaneous Reactions to Ionizing Radiation Therapy. Dermatol. Ther. 2016, 6, 185-206. [CrossRef]

14. Salvo, N.; Barnes, E.; van Draanen, J.; Stacey, E.; Mitera, G.; Breen, D.; Giotis, A.; Czarnota, G.; Pang, J.; De Angelis, C. Prophylaxis and Management of Acute Radiation-Induced Skin Reactions: A Systematic Review of the Literature. Curr. Oncol. 2010, 17, 94-112. [CrossRef] [PubMed]

15. Kole, A.J.; Kole, L.; Moran, M.S. Acute radiation dermatitis in breast cancer patients: Challenges and solutions. Breast Cancer: Targets Ther. 2017, 9, 313-323. [CrossRef] [PubMed]

16. Meimeti, E.; Kafanas, A.; Pavlou, P.; Evangelatou, A.; Tsouparelou, P.; Kanellopoulos, S.; Kipouros, P.; Koliarakis, N.; Leonis, G.; Ioannou, E.; et al. Topical Treatment of Skin Injury Inflicted in Mice by X-Ray Irradiation. Ski. Pharmacol. Physiol. 2018, 31, 175-183. [CrossRef] [PubMed]

17. Huang, C.-J.; Hou, M.-F.; Luo, K.-H.; Wei, S.-Y.; Huang, M.-Y.; Su, S.-J.; Kuo, H.-Y.; Yuan, S.-S.F.; Chen, G.-S.; Hu, S.C.-S.; et al. RTOG, CTCAE and WHO criteria for acute radiation dermatitis correlate with cutaneous blood flow measurements. Breast 2015, 24, 230-236. [CrossRef]

18. Singh, M.; Alavi, A.; Wong, R.; Akita, S. Radiodermatitis: A Review of Our Current Understanding. Am. J. Clin. Dermatol. 2016, 17, 277-292. [CrossRef]

19. Wong, R.K.S.; Bensadoun, R.-J.; Boers-Doets, C.B.; Bryce, J.; Chan, A.; Epstein, J.B.; Eaby-Sandy, B.; Lacouture, M.E. Clinical practice guidelines for the prevention and treatment of acute and late radiation reactions from the MASCC Skin Toxicity Study Group. Support. Care Cancer 2013, 21, 2933-2948. [CrossRef]

20. McQuestion, M. Evidence-Based Skin Care Management in Radiation Therapy: Clinical Update. Semin. Oncol. Nurs. 2011, 27, e1-e17. [CrossRef]

21. Harris, R.; Probst, H.; Beardmore, C.; James, S.; Dumbleton, C.; Bolderston, A.; Faithfull, S.; Wells, M.; Southgate, E. Radiotherapy skin care: A survey of practice in the UK. Radiogr. 2012, 18, 21-27. [CrossRef]

22. Kavanagh, S.; De Jong, A. Care of burn patients in the hospital. Burn. 2004, 30, A2-A6. [CrossRef]

23. Kamoun, E.A.; Kenawy, E.-R.S.; Chen, X. A review on polymeric hydrogel membranes for wound dressing applications: PVA-based hydrogel dressings. J. Adv. Res. 2017, 8, 217-233. [CrossRef]

24. Mogoşanu, G.D.; Grumezescu, A.M. Natural and synthetic polymers for wounds and burns dressing. Int. J. Pharm. 2014, 463, 127-136. [CrossRef] [PubMed]

25. Romano, I.; Summa, M.; Heredia-Guerrero, J.A.; Spano', R.; Ceseracciu, L.; Pignatelli, C.; Bertorelli, R.; Mele, E.; Athanassiou, A. Fumarate-loaded electrospun nanofibers with anti-inflammatory activity for fast recovery of mild skin burns. Biomed. Mater. 2016, 11, 041001. [CrossRef] [PubMed]

26. Kotroni, E.; Simirioti, E.; Kikionis, S.; Sfiniadakis, I.; Siamidi, A.; Karalis, V.; Vitsos, A.; Vlachou, M.; Ioannou, E.; Roussis, V.; et al. In Vivo Evaluation of the Anti-Inflammatory Activity of Electrospun Micro/Nanofibrous Patches Loaded with Pinus halepensis Bark Extract on Hairless Mice Skin. Materials 2019, 12, 2596. [CrossRef]

27. Hajiali, H.; Summa, M.; Russo, D.; Armirotti, A.; Brunetti, V.; Bertorelli, R.; Athanassiou, A.; Mele, E. Alginate-lavender nanofibers with antibacterial and anti-inflammatory activity to effectively promote burn healing. J. Mater. Chem. B 2016, 4, 1686-1695. [CrossRef] [PubMed]

28. Konwarh, R.; Karak, N.; Misra, M. Electrospun cellulose acetate nanofibers: The present status and gamut of biotechnological applications. Biotechnol. Adv. 2013, 31, 421-437. [CrossRef]

29. Weng, L. Smart Electrospun Nanofibers for Controlled Drug Release: Recent Advances and New Perspectives. Curr. Pharm. Des. 2015, 21, 1944-1959. [CrossRef]

30. Kikionis, S.; Ioannou, E.; Toskas, G.; Roussis, V. Electrospun biocomposite nanofibers of ulvan/PCL and ulvan/PEO. J. Appl. Polym. Sci. 2015, 132, 42153. [CrossRef]

31. Thenmozhi, S.; Dharmaraj, N.; Kadirvelu, K.; Kim, H.Y. Electrospun nanofibers: New generation materials for advanced applications. Mater. Sci. Eng. B 2017, 217, 36-48. [CrossRef]

32. Anstey, A.; Chang, E.; Kim, E.S.; Rizvi, A.; Kakroodi, A.R.; Park, C.B.; Lee, P.C. Nanofibrillated polymer systems: Design, application, and current state of the art. Prog. Polym. Sci. 2021, 113, 101346. [CrossRef]

33. Teo, W.E.; Ramakrishna, S. A review on electrospinning design and nanofibre assemblies. Nanotechnology 2006, 17, R89-R106. [CrossRef] [PubMed]

34. Greiner, A.; Wendorff, J.H. Electrospinning: A Fascinating Method for the Preparation of Ultrathin Fibers. Angew. Chem. Int. Ed. 2007, 46, 5670-5703. [CrossRef] [PubMed]

35. Vlachou, M.; Kikionis, S.; Siamidi, A.; Kyriakou, S.; Tsotinis, A.; Ioannou, E.; Roussis, V. Development and Characterization of Eudragit ${ }^{\circledR}$-Based Electrospun Nanofibrous Mats and Their Formulation into Nanofiber Tablets for the Modified Release of Furosemide. Pharmaceuticals 2019, 11, 480. [CrossRef]

36. Kikionis, S.; Ioannou, E.; Andrén, O.C.J.; Chronakis, I.S.; Fahmi, A.; Malkoch, M.; Toskas, G.; Roussis, V. Nanofibrous nonwovens based on dendritic-linear-dendritic poly (ethylene glycol) hybrids. J. Appl. Polym. Sci. 2017, 135, 45949. [CrossRef]

37. Cheng, H.; Yang, X.; Che, X.; Yang, M.; Zhai, G. Biomedical application and controlled drug release of electrospun fibrous materials. Mater. Sci. Eng. C 2018, 90, 750-763. [CrossRef]

38. Kikionis, S.; Ioannou, E.; Konstantopoulou, M.; Roussis, V. Electrospun Micro/Nanofibers as Controlled Release Systems for Pheromones of Bactrocera oleae and Prays oleae. J. Chem. Ecol. 2017, 43, 254-262. [CrossRef] 
39. Liu, M.; Duan, X.P.; Li, Y.M.; Yang, D.P.; Long, Y.Z. Electrospun nanofibers for wound healing. Mater. Sci. Eng. C Mater. Biol. Appl. 2017, 76, 1413-1423. [CrossRef]

40. Schiller, G. Therapeutic use of Aleppo Pine (Pinus halepensis Mill.). In Springer-Medicinal and Aromatic Plants of the Middle-East, 1st ed.; Yaniv, Z., Dudai, N., Eds.; Springer: Dordrecht, The Netherlands, 2014; Volume 2, pp. 215-224.

41. Süntar, I.; Tumen, I.; Ustün, O.; Keles,, H.; Akkol, E.K. Appraisal on the wound healing and anti-inflammatory activities of the essential oils obtained from the cones and needles of Pinus species by in vivo and in vitro experimental models. J. Ethnopharmacol. 2012, 139, 533-540. [CrossRef]

42. Ioannou, E.; Koutsaviti, A.; Tzakou, O.; Roussis, V. The genus Pinus: A comparative study on the needle essential oil composition of 46 pine species. Phytochem. Rev. 2014, 13, 741-768. [CrossRef]

43. Zoumpliou, V.; Stamatiadi, M.; Vassiliadis, C.; Rallis, M.; Papaioannou, G.T.; Liakos, S.; Angelou, A.; Daskalaki, S.; Kyriazi, M.; Roussis, V.; et al. Effect of Cigarette Smoke on Diabetic Skin and Protection with Topical Administration of Pinus halepensis Extract. Am. J. Plant. Sci. 2014, 5, 3964-3973. [CrossRef]

44. Guri, A.; Kefalas, P.; Roussis, V. Antioxidant potential of six pine species. Phytother. Res. 2006, 20, 263-266. [CrossRef] [PubMed]

45. Fekiha, N.; Allalia, H.; Merghachea, S.; Chaïb, F.; Merghachec, D.; El Amine, M.; Djabou, N.; Musellib, A.; Tabtia, B.; Costab, J. Chemical composition and antibacterial activity of Pinus halepensis Miller growing in West Northern of Algeria. Asian Pac. J. Trop. Dis. 2014, 4, 97-103. [CrossRef]

46. Petri, A.; Alexandratou, E.; Kyriazi, M.; Rallis, M.; Roussis, V.; Yova, D. Combination of Fospeg-IPDT and a natural antioxidant compound prevents photosensitivity in a murine prostate cancer tumour model. Photodiagn. Photodyn. Ther. 2012, 9, 100-108. [CrossRef] [PubMed]

47. Hashemikia, S.; Farhangpazhouh, F.; Parsa, M.; Hasan, M.; Hassanzadeh, A.; Hamidi, M. Fabrication of ciprofloxacin-loaded chitosan/polyethylene oxide/silica nanofibers for wound dressing application: In vitro and in vivo evaluations. Int. J. Pharm. 2021, 597, 120313. [CrossRef]

48. Mokhena, T.C.; Mochane, M.J.; Mtibe, A.; John, M.J.; Sadiku, E.R.; Sefadi, J.S. Electrospun Alginate Nanofibers Toward Various Applications: A Review. Materials 2020, 13, 934. [CrossRef]

49. Teixeira, M.A.; Paiva, M.C.; Amorim, M.T.P.; Felgueiras, A.H.P. Electrospun Nanocomposites Containing Cellulose and Its Derivatives Modified with Specialized Biomolecules for an Enhanced Wound Healing. Nanomaterials 2020, 10, 557. [CrossRef]

50. Schmeel, L.C.; Koch, D.; Stumpf, S.; Leitzen, C.; Simon, B.; Schüller, H.; Vornholt, S.; Schoroth, F.; Müdder, T.; Röhner, F.; et al. Prophylactically applied Hydrofilm polyurethane film dressings reduce radiation dermatitis in adjuvant radiation therapy of breast cancer patients. Acta Oncol. 2018, 57, 908-915. [CrossRef] [PubMed]

51. Schmeel, L.C.; Koch, D.; Schmeel, F.C.; Bücheler, B.; Leitzen, C.; Mahlmann, B.; Kunze, D.; Heimann, M.; Brüser, D.; Abramian, A.-V.; et al. Hydrofilm Polyurethane Films Reduce Radiation Dermatitis Severity in Hypofractionated Whole-Breast Irradiation: An Objective, Intra-Patient Randomized Dual-Center Assessment. Polymer 2019, 11, 2112. [CrossRef]

52. Herst, P.M.; Bennett, N.C.; Sutherland, A.E.; Peszynski, R.I.; Paterson, D.B.; Jasperse, M.L. Prophylactic use of Mepitel Film prevents radiation-induced moist desquamation in an intra-patient randomised controlled clinical trial of 78 breast cancer patients. Radiother. Oncol. 2014, 110, 137-143. [CrossRef] [PubMed]

53. Yan, J.; Yuan, L.; Wang, J.; Li, S.; Yao, M.; Wang, K.; Herst, P.M. Mepitel Film is superior to Biafine cream in managing acute radiation-induced skin reactions in head and neck cancer patients: A randomised intra-patient controlled clinical trial. J. Med. Radiat. Sci. 2020, 67, 208-216. [CrossRef] [PubMed] 